\title{
EL PAPEL DEL AUTOR Y LA CONDICIÓN TESTIMONIAL DE LAS NOVELAS NO, MI GENERAL DE IRENE LOZANO Y HAY ALGO QUE NO ES COMO ME DICEN DE JUAN JOSÉ MILLÁS
}

\author{
THE ROLE OF THE AUTHOR AND THE TESTIMONIAL CONDITION OF \\ THE NOVELS NO, MI GENERAL BY IRENE LOZANO AND HAY ALGO QUE NO ES \\ COMO ME DICEN BY JUAN JOSÉ MILLÁS \\ MILICA LILIC \\ UNIVERSIDAD INTERNACIONAL DE LA RIOJA \\ milica.lilic@unir.net
}

Recibido: 04.04.2020

Aceptado: 06.12.2020

\begin{abstract}
RESUMEN: El presente trabajo parte del concepto de la novela testimonial y sus manifestaciones en la narrativa española actual, para analizar los elementos documentales y las técnicas ficcionales integradas en las obras No, mi general de Irene Lozano y Hay algo que no es como me dicen de Juan José Millás. El cambio en el enfoque temático que presentan estas novelas -ambas relatan historias reales sobre el acoso laboral y sexual a las mujeres en el Ejército español y el Ayuntamiento de Ponferrada, respectivamente-, permitirá estudiar su estructura particular, así como la importancia del papel del autor y su intervención real y parcial en el caso. De esta forma, se afirmará el carácter colectivo y denunciante de estas obras en cuanto a la mencionada problemática social emergente. Asimismo, se pondrá énfasis especial en la subjetivización, elemento que demuestra la condición testimonial de estas novelas, esto es, afirma el desarrollo de una serie de técnicas que objetivizan los hechos, por una parte, y certifica la presencia de los mecanismos que aportan a la narrativización del relato, por otra. Finalmente, se distinguirán dos niveles de narración: la historia de la protagonista y la historia del narrador. La primera narra un caso real de acoso desde la perspectiva de la víctima, esto es, reinterpreta la verdad oficial y reconstruye la realidad, mientras que la segunda adquiere una dimensión modélica y apela a todo un colectivo de mujeres acosadas en el lugar de trabajo.
\end{abstract}

Palabras clave: Novela testimonial, valor documental, subjetivización, Zaida Cantera, Nevenka Fernández 
ABSTRACT: This study starts from the concept of the testimonial novel and its manifestations in the current Spanish narrative, in order to analyze the documentary elements and the fictional techniques integrated into the works No, mi general by Irene Lozano and Hay algo que no es como me dicen by Juan José Millás. The change in the thematic approach presented by these novels -both tell real stories about mobbing and sexual harassment of women in the Spanish Army and Ponferrada City Council, respectively-, will allow to study their particular structure, as well as the importance of the authors' role and their real and partial intervention in the case. In this way, the collective and denouncing nature these novels have regarding the aforementioned emerging social problem will be affirmed. Likewise, a special emphasis will be put on subjectivization, an element that proves the testimonial condition of these novels, that is, it affirms the development of a series of techniques that objectify the facts, on the one hand, and certifies the presence of the mechanisms that contribute to the narrativization of the story, on the other. Finally, two levels of narration will be distinguished: the story of the protagonist and the story of the narrator. The first one narrates a real case of harassment from the perspective of the victim, that is, it reinterprets the official truth and reconstructs reality, while the second one acquires a model dimension and appeals to a whole group of harassed women in the workplace.

Keywords: Testimonial Novel, Documentary Value, Subjectivization, Zaida Cantera, Nevenka Fernández

\section{7 the}

\section{INTRODUCCIÓN}

El desarrollo de una comunidad global y la predominante lógica del mercado mundial, característicos del siglo xxI, han cambiado la preocupación y la sensibilización por determinadas cuestiones sociales y, en consecuencia, han potenciado la presencia de estos temas en la literatura actual. En ese sentido, aunque el fenómeno del acoso en el mundo laboral no resulta ser novedoso, sí aporta un valor adicional y cobra mayor protagonismo en la sociedad actual, y como tal, en la propia narrativa.

Dentro del marco de las obras que centran su trama en esta conducta social adversa, se distinguen particularmente las novelas testimoniales que, debido a su dicotomía realidad-ficción y su carácter biográfico colectivo, presentan historias reales a través de las técnicas narrativas, tomando una actitud crítica y denunciante.

Ese es el caso de las novelas Hay algo que no es como me dicen. El caso de Nevenka Fernández contra la realidad de Juan José Millás y No, mi general de Irene Lozano, ambas centradas en el acoso laboral y sexual femenino que se pro- 
dujo en el Ayuntamiento de Ponferrada y el Ejército Español, respectivamente. El caso de Nevenka, la joven concejala que fue víctima del acoso ejercido por su jefe, el entonces alcalde Ismael Álvarez, se dio entre 1999 y 2001. Millás realizó la investigación sobre el caso entre 2001 y 2003 y publicó el libro en 2004. Por otra parte, el acoso de Zaida Cantera, la capitán de las Fuerzas Armadas que fue víctima de su superior directo, el teniente coronel Isidro José de Lezcano-Mújica Núñez, se produjo desde el 2008 hasta el 2014 y la novela se publicó un año más tarde, en 2015.

Teniendo en cuenta la naturaleza documental de estas dos obras, el presente estudio propone establecer una relación entre esta problemática emergente de la sociedad moderna y el testimonio como herramienta literaria. Para ello, se partirá del concepto de la novela testimonial, para explicar el carácter extraoficial de las dos obras mencionadas (las historias las cuentan las víctimas) y su estructura interna.

\section{LA NOVELA TESTIMONIAL}

La novela testimonial se caracteriza por establecer "la conexión directa con la realidad extratextual, los elementos del relato tienen su correspondencia inmediata en el mundo exterior al texto" (Huertas Uhagón 1994: 167). ${ }^{1}$ Sin embargo, estos relatos de no-ficción ${ }^{2}$ no son una simple trascripción de hechos, sino que representan una construcción narrativa compleja donde lo real y lo ficcional establecen una relación peculiar. Esto quiere decir que, aunque el material del que parten no puede sufrir modificaciones por exigencias de la obra (entrevistas, grabaciones, documentos o propios recuerdos del testigo), sí se transforma la forma en la que este se utiliza para construir historias. Así se crean relatos que, lejos de representar un simple reflejo de la realidad, construyen una nueva realidad regida por leyes propias o, mejor dicho, una versión particular de esa nueva realidad "con la que se denuncia la 'verosimilitud' de otras versiones" (Amar Sánchez 1990: 447). De ese modo, debido a las experiencias subjetivas y numerosas vías que existen para darle forma al material fijo (dependiendo del modo en el que se organiza, fragmenta, recopila y manipula lo "real"), en una novela testimonial la multitud de realidades se convierte en una multitud de representaciones de esas realidades, que, por su parte, depende de las concepciones culturales y determinados factores sociales.

De esa forma, la novela testimonial resulta ser un oxímoron que crea dos paradojas paralelas: la de parecer un texto de ficción cuando el lector sabe que los hechos realmente ocurrieron y la de contar fielmente lo ocurrido cuando la estructura y el lenguaje crean otra realidad distinta. Así, este género juega en los límites de la forma, tanto uniendo ambas partes como contradiciendo una a la

\footnotetext{
${ }^{1}$ A lo largo de la segunda mitad del siglo xx aparecieron diferentes denominaciones para referirse a este tipo de novelas: testimonio, novela-testimonio, narración o novela documental, nonfiction novel, socioliteratura, literatura factográfica, etc. (Beverley 1987: 9).

2 Entre otros teóricos y críticos, el término del "relato de no-ficción" lo utiliza Amar Sánchez (1992) en su estudio donde intenta determinar los rasgos particulares del género.
} 
otra, de manera que lo ficticio crea una dependencia de -y un conflicto con- lo real. Aunque nada de lo que cuenta es inventado, inventa una forma de contar esa experiencia. Por lo tanto, es preciso considerar simultáneamente la condición literaria del relato y su valor documental, ya que "el texto funciona como una instancia transformadora que actúa entre los sucesos y el lector" (Amar Sánchez 1990: 451).

Para valorar este tipo de discurso, algunos críticos hispanoamericanos de la segunda mitad del siglo xx (Beverley 1987) se apoyan principalmente en elementos extratextuales (sociales, políticos, antropológicos), dejando de lado el grado de acercamiento a la forma y el lenguaje literario, y aseguran que solamente los pertenecientes a clases bajas, los reprimidos, analfabetos y marginales pueden ser narradores-testigos, de manera que se pierde el concepto tradicional del autor, ya que "ha sido reemplazado por la función de un compilador" (Beverley 1987: 12), quien ahora intermedia entre ese narrador popular y el lector, creando un texto de valor testimonial y sin pretensiones literarias. Consideran que solo contando historias de los reprimidos podrán contrastar la historia oficial, representada normalmente por los poderosos:

Official history too often has been the history of "great" individuals rather than the history of the people. By emphasizing individuality, the voice of the people was silenced. Testimonial discourse is reversing this tendency and speaks for those who previously were not allowed to speak. Aside from witnessing la vida real ("real life"; as Barnett called it), it points at all the previously falsifying accounts of reality. It throws a wrench into Western notions of reality and unmasks "reality" as fiction and through its witnessing posture presents real life. (Gugelberger y Kearney 1991: 8) ${ }^{3}$

Destacan, además, que el narrador, representado por un escritor que goza de un estatus más elevado en la sociedad, tampoco pertenece a la misma clase social que el lector de su relato (el narrador, normalmente siendo analfabeto, ni siquiera puede leer su propia historia).

Hoy en día, esa tendencia de convertir al autor en un mero intermediador y de valorar únicamente aquellas obras escritas sobre la vida y las experiencias de personas anónimas y de clase baja que no han podido expresarse solas, se considera obsoleta, ya que quedan registradas numerosas novelas testimoniales elaboradas por autores cultos y de estatus elevado, que relatan tanto historias ajenas (Poniatowska en México, Barnet en Cuba) como su propia experiencia (Edwards en Chile, Leñero en México), creando deliberadamente un nuevo género literario y llevándolo a su máxima expresión. Cabe destacar, finalmente, que no es necesario conocer la clase social del autor o narrador, su procedencia u oficio para poder certificar la credibilidad de los hechos y la calidad de la novela. Basta con ser testigo de hechos reales, representar un colectivo de afectados

\footnotetext{
${ }^{3}$ Gugelberger y Kearney basaron sus estudios en las novelas latinoamericanas donde este género se produjo como consecuencia de las revoluciones y la opresión que sufrió el pueblo, hecho en el que apoyaron su teoría sobre la exclusividad de testigos oprimidos.
} 
por el mismo problema o tener una interpretación de sucesos que se enfrenta a la versión oficial, para convertirse en el narrador de un texto de no-ficción.

Beverley considera que el narrador "siempre involucra cierta urgencia o necesidad de comunicación" (1987: 9), ya que su situación oprimida como protagonista y el carácter colectivo de su relato lo exigen. Sin embargo, aunque los temas contados sean de carácter socio-político o histórico, el novelista principalmente transcribe las experiencias vividas por su interlocutor, o bien relata sus propias, convirtiendo esa historia de la sociedad en la historia de un personaje, en microhistoria. Centrada en lo particular, a través de un plano individual, la narración obtiene elementos subjetivistas, ya que el autor narra desde dentro, es decir, ve de cerca a todos los personajes y se ve implicado -si aún no lo estáen el asunto. Lo sabe todo, pero representa la realidad que le interesa, dejando ambiguas las partes que no siente necesidad de aclarar. "Se llega así, del máximo objetivismo atestiguador, al máximo subjetivismo creativo" (Sobejano 1986: 94). Así se produce un constante vaivén entre el narrador (el que relata la historia y contribuye a su subjetivización) y el autor (representado por un personaje real quien ha vivido esas experiencias o bien, quien investiga sobre lo ocurrido). Finalmente, el papel del autor-gestor del relato incluye su responsabilidad ante el lector y el compromiso de no modificar el material fijo, es decir, de transmitir los hechos reales tal y como sucedieron, ya sea apoyándose en la experiencia propia o en otras fuentes de información que él juzgue como absolutamente veraces.

Sin embargo, aunque los críticos determinan sus rasgos principales, este género literario carece de una definición y de un nombre unívocos. De hecho, muchos aspectos quedan cuestionables, ya que ningún estudio que se ha propuesto explicarlo ha terminado de ofrecer una teoría que abarque todas las obras pertenecientes al género. Huertas Uhagón destaca "la necesidad o no de la absoluta veracidad de los hechos relatados, la función principal de este tipo de discurso, las características del testimoniante (singular, plural, verdadero, ficticio) o las cualidades del referente histórico (reconocible, desconocido, presente, pasado)" (1994: 169), como algunos de los aspectos más discutibles. De ahí que este género se haya concebido como híbrido o impuro, ya que contiene características de diferentes formas literarias, como son el ensayo, la crónica, el reportaje o el diario. En los casos de novelas en las que el autor es narrador y protagonista, incluso se podría confundir con una autobiografía. Sin embargo, aunque cuenta historias individuales y personales, debido a la temática social y comprometida de la obra, el autor en realidad crea un personaje colectivo que representa toda una clase o un grupo determinado de la sociedad. Precisamente ese carácter colectivo que tiene la distingue de la autobiografía, ya que esta última es de carácter individualista y no permite que el protagonista de la obra presente un prototipo de un determinado grupo de la comunidad, cosa que queda explicada por Beverley:

Sin embargo, hay implícito en la autobiografía como género una postura individualista, ya que como forma narrativa depende de un sujeto narrador coherente, dueño de sí mismo, que se apropia de la literatura precisamente para manifestar la singularidad de su experiencia, su estilo propio. La autobiografía 
construye para el lector el imaginario liberal de un yo autónomo e imperante como la forma "natural" de existencia tanto pública como privada. Por contraste, el yo testimonial funciona más como lo que en la lingüística llaman un "dispositivo" (shifter) que puede ser asumido por cualquiera. (Beverly 1987: 13)

Además, aunque relate acontecimientos históricos, tampoco se puede interpretar como un simple texto histórico. La historia es una representación objetiva del pasado que establece una clara distancia entre los hechos y los individuos involucrados, mientras que la novela testimonial adopta una actitud extraoficial y reproduce ese pasado a base de memorias, recuerdos y testimonios, implicando emociones, inquietudes, críticas y experiencias vividas por los involucrados.

En muchas ocasiones, debido a su afinidad con otras formas, la novela testimonial se ha definido erróneamente "por lo que él no es, por su grado de semejanza con el periodismo o con la novela ficcional y no se piensa su singularidad ni su propuesta en tanto discursivo nuevo" (Amar Sánchez 1992: 14). Este postulado sostiene que la novela testimonial no solo que no sea un texto puramente imaginario ni mantenga una distancia objetiva en la narración, sino que tampoco es una mezcla de géneros inestable. Al contrario, se produce una ruptura entre la realidad y la ficción, que sitúa a la novela testimonial en una posición intersticial entre los géneros literarios. En ese sentido, destaca un elemento en particular que afirma su naturaleza singular: la subjetivización (Amar Sánchez 1990: 449). Consiste en aplicar la técnica de narrativización o ficcionalización para convertir las figuras provenientes del mundo real en narradores y personajes, esto es, para subjetivizarlas, de tal manera que simultáneamente pertenezcan al espacio real y al narrativo. En otras palabras, se respeta la base real, pero la información que se plantea ante el lector es selectiva y se trabajan minuciosamente los fragmentos y detalles, de manera que todo el argumento se convierte en una historia alternativa, en una realidad ficcionalizada.

Por otra parte, la confusión por entender este género se crea por asociar el concepto de ficción con mentira y el de realidad con verdad, cuando en realidad ninguno de los dos se puede interpretar como algo absoluto. Al contrario, son una construcción cultural e históricamente variable que depende de las normas de la sociedad y la época, de manera que, en el caso de novelas testimoniales, los límites entre estas dos categorías se ven borrosos y cambiantes. Así, la realidad se interpreta como una reconstrucción de los hechos (no es una verdad absoluta, ya que el texto está construido por una serie de acontecimientos seleccionados, mientras otros quedaron omitidos) y la ficción como el efecto de la forma de narrar esos hechos. Lejos de representar un simple conjunto de procedimientos literarios, esa forma depende también de los factores extralingüísticos y del propio contenido del relato, lo que permite ese tránsito constante de lo real a lo textual:

Si la ficcionalidad -como se dijo-es un efecto del relato en el que los códigos narrativos organizan los diferentes registros testimoniales, el género elabora una ecuación particular en la que construir, narrar y ficcionalizar - de algún modo interdependientes y equivalentes- permiten acceder a la verdad de los 
hechos: en el relato puede desarrollarse una verdad que la información periodística u oficial ignora, modifica u oculta. (Amar Sánchez 1992: 34-35)

Esa verdad pertenece a los que relatan la historia -que es subjetivizada- y son tanto el narrador (autor o testigo) como los personajes (testigos y participantes en acontecimientos reales), por lo que su papel y la postura que toman en la creación de la obra representan otro de los rasgos fundamentales que definen la particularidad del género.

Las novelas testimoniales han sido ampliamente tratadas en la literatura del siglo pasado, especialmente en la región de América Latina y Estados Unidos, donde en los años 60 y 70 llegaron a ser la forma literaria predominante (New Journalism en Norteamérica y literatura testimonial en América Latina). No obstante, aunque principalmente ocupan aquellas culturas que han sido colonizadas por metrópolis europeas, también se hallan presentes en el escenario europeo. La teoría de la presencia del género en distintas culturas y regiones la defiende Dupláa (1996: 64), señalando que el discurso testimonial no es patrimonio de ningún territorio, puesto que, restringiéndolo a una zona, se reduciría también su problemática.

La modalidad española de las novelas con elementos testificativos estuvo especialmente presente en la península en los años posteriores a la Guerra Civil, ${ }^{4}$ cuando el ejercicio del poder cayó en manos del dictador Francisco Franco. Durante este lapso de tiempo, fueron apareciendo novelistas observadores, militantes o intérpretes (Sobejano 1986: 98). Los años de censura durante el franquismo quedaron sustituidos por los años de la transición, de manera que empezaron a cultivarse numerosas tendencias narrativas, tratándose en muchos casos de géneros alternativos. Durante este tiempo en España se ha detectado una notable presencia de "autores relevantes con el doble perfil de dedicación simultánea al periodismo y a la literatura" (Torregrosa Carmona y Gaona Pisonero 2013: 793), entre ellos Juan José Millás, Manuel Vicent y Maruja Torres. Mientras los textos pertenecientes al código del lenguaje periodístico convencional se caracterizan por una perspectiva alejada, las construcciones impersonales y muy escasa descripción de los actores de la historia, estos cuentan con una condición ambigua de sus personajes que constantemente están entre el mundo narrativo y el real, creando simultáneamente un texto testimonial y ficcional. En el primer caso se trata de disimular al enunciador, de neutralizar su voz, mientras que en el segundo la presencia del narrador y su postura sobre el asunto quedan bien expuestas. Además, el periodismo en sí se relaciona con columnas, revistas o periódicos y como tal, es de carácter más transitorio, mientras que la novela testimonial abandona esa nota de inmediatez periodística y constituye su propia tradición.

\footnotetext{
${ }^{4}$ En los años de la guerra se publicó Contraataque de Ramón J. Sender, primero en su traducción inglesa y francesa en 1937 y un año más tarde en su versión original. Este testimonio en primera persona sobre la experiencia personal del autor tiene una finalidad comprometida, ya que procura despertar la consciencia del lector en cuanto a la insurgencia fascista.
} 
En su artículo en El País en el que destaca la relación entre la narrativa y las noticias, González Harbour explica la predominación de la realidad ante la ficción en los novelistas del siglo XXI, apoyándose en las palabras de Juan Cerezo, editor de Tusquets:

Y saturados de ficción, o de los trucos de cierta ficción, muchos novelistas recurren a la crónica, la autobiografía, a la documentación para incrementar la eficacia de la verosimilitud. La autoficción, que fue motivo de exploración metaliteraria en tantas novelas, se ha ido convirtiendo en autoconfesión como estrategia necesaria de credibilidad. El narrador testigo es ahora narrador personaje y muchas veces objeto de autoanálisis en paralelo y confundido con la historia que quiere contar, sin ocultar su punto de vista o su implicación emocional en lo que cuenta. (Cerezo 2014)

Nuevamente se establece la diferencia entre estos dos conceptos literarios: la imaginación que pretende asimilarse a la verdad y la realidad que asume la forma de la ficción dentro de un texto narrativo. Favoreciendo el segundo, González Harbour (2014) sostiene que la realidad es la materia prima en los textos contemporáneos, de manera que se sustituye por la veracidad.

Así, las circunstancias especiales de la sociedad actual han provocado un resurgimiento de la narrativa testimonial, que ya no pone interés principal en temas totalizadores (guerras, represiones, dictaduras, etc.), sino que se centra en los problemas y retos que el hombre moderno afronta en su ámbito familiar y laboral. De ahí la temática del acoso laboral y sexual que abordan los autores de No, mi general y Hay algo que no es como me dicen, apoyándose en las características del testimonio literario para expresar su postura y transmitir su propio juicio.

\section{El PAPEL DEL AUtOR EN LAS NOVELAS TESTIMONIALES}

Tal y como ha quedado señalado, el hecho de exponer una intrahistoria, un hecho desconocido parcialmente o en su totalidad, no solo permite que estas dos obras firmadas por Lozano y Millás, respectivamente, obtengan el valor documental, sino que también subjetiviza la historia y le posibilita al autor narrativizar el material del que dispone. Esto quiere decir que Millás y Lozano son partícipes activos de las historias que cuentan y se caracterizan por un compromiso ético muy elevado, ya que su intervención a lo largo de la obra es tan constante como parcial. Así, estos autores crean una realidad distinta a la oficial. De ahí la observación de Chillón, quien aclara que la realidad es un concepto múltiple:

No existe una sola realidad objetiva externa a los individuos, sino múltiples realidades subjetivas, innúmeras experiencias. Y esas realidades subjetivas múltiples e inevitables adquieren sentido para uno y son comunicables para los demás en la medida en que son verbalizadas: engastadas en palabras y vertebradas en enunciados lingüísticos. (Chillón 1999: 28-29) 
En ese sentido, cabe relacionar las realidades de las dos novelas con las tendencias literarias de sus autores. Irene Lozano es política, periodista y escritora, cuya obra se define principalmente por ensayos de no ficción. Ha publicado, además, dos novelas de denuncia: la tratada en el presente trabajo y Si sufrir fuera sencillo (2018). La segunda obra, inspirada en la historia real del comandante americano Claude Eatherly, quien realizó el vuelo de reconocimiento meteorológico sobre Hiroshima unas horas antes del bombardeo, cuestiona los límites de la responsabilidad moral humana. Tal planteamiento del argumento de la novela demuestra nuevamente el fuerte compromiso ético presente en la narrativa de Lozano, que interpreta la literatura como una herramienta para afrontar distintas problemáticas de la sociedad moderna. Ese compromiso con la realidad de Lozano supera los límites de lo intratextual en No, mi general, ya que la autora utiliza su posición política para escribir esta obra y relatar la otra parte de la historia de un caso de acoso sexual en el Ejército.

Juan José Millás, por su parte, cuenta con una obra consolidada y es uno de los referentes más destacados de la narrativa actual en español. La complejidad se sus tendencias literarias se refleja en la naturaleza transgenérica de muchos de sus textos, en la dualidad entre la simetría y la desproporción, en sus relaciones con lo fantástico y su propósito de articular lo real con lo irreal. En ese sentido, Augusto Ayuso observa que, para Millás, "la novela es un simulacro y la vida está ahí, con sus enigmas y sus interrogantes, siempre necesitada del sueño, de su sacudida desconcertante y misteriosa, cuando no se confunde con él" (2001: 34). Sobejano, además, contempla la extrañeza como una cualidad que ocupa muchas de las obras de Millás:

A la extrañeza argumental y temática conviene agregar, para definir con precisión la novelística de JJM, otros dos conceptos: extrañación y extrañamiento. Si la extrañeza es una cualidad de la materia tematizada, la extrañación sería el efecto enajenador del mundo descrito sobre la conciencia que vive o describe ese mundo, y el extrañamiento el modo de expresar -por la estructuración o por el lenguaje- la extrañación y la extrañeza. (Sobejano 2007: 501)

Estos elementos también están presentes en Hay algo que no es como me dicen donde el autor-narrador estudia a lo largo de la obra el proceso de extrañamiento de su protagonista. En cuanto a las (ir)realidades de la narrativa de Millás, la propia naturaleza documental de esta obra confirma la presencia de esta dualidad. De hecho, se podría afirmar que la relación real-irreal es una constante en cualquier novela testimonial.

A diferencia de un informe periodístico, que aparte de no contar con elementos literarios, carece de la opinión personal del autor, en estas novelas se identifica la intención del escritor de trasmitir su juicio, de manera que, aunque relate hechos reales, su texto no es totalmente objetivo. El autor transforma el material fijo de tal forma que personaliza un pasado desconocido y lo hace público mediante su escritura. Extrae del anonimato solo una parte determinada de esa intrahistoria, cuestionando así la verdad absoluta presentada por la versión oficial. Dependiendo del estatuto del autor, se puede hablar de la escritura do- 
cumental de carácter biográfico o autobiográfico. Esto es, del autor-narradorintérprete o del autor-narrador-protagonista. Confrontando estos dos tipos de escritura a textos puramente ficcionales, Lejeune afirma:

\begin{abstract}
Por oposición a todas las formas de la ficción, la biografía y la autobiografía son textos referenciales: de la misma manera que el discurso científico o histórico, pretenden aportar una información sobre una "realidad" exterior al texto, y se someten, por lo tanto, a una prueba de verificación. Su fin no es la mera verosimilitud sino el parecido a lo real; no "el efecto de realidad" sino la imagen de lo real. Todos los textos referenciales conllevan, por lo tanto, lo que yo denominaría "pacto referencial", implícito o explícito, en el que se incluyen una definición del campo de lo real al que se apunta y un enunciado de las modalidades y del grado de parecido a los que el texto aspira. (Lejeune 1994: 76)
\end{abstract}

Las dos novelas objeto del presente estudio se caracterizan por el primer caso, el del autor-narrador-intérprete, donde se establece un diálogo entre el protagonista de los hechos (Nevenka y Zaida) y el escritor que los transcribe (Millás y Lozano). El papel del narrador lo puede desarrollar cualquiera de estos dos, de manera que en determinadas obras principalmente es el autor el que hace de narrador, pero en ciertos fragmentos su voz desaparece y la palabra del protagonista se apodera del discurso. Además, Millás hace destacar la presencia de su interlocutora y explica con detalles las entrevistas que obtuvo con ella, nombrando claramente el lugar de sus encuentros (Talavera de la Reina, en casa de los padres de su novio Lucas donde esta buscó su refugio), con el propósito de aumentar el objetivismo del relato. Además, hablando en primera persona y apoyándose en un marco temporal muy concreto, deja conocer incluso la forma en la que recogía la información principal y en la que se desarrollaban sus encuentros con la protagonista: "Nevenka y yo nos sentábamos a una mesa camilla de aquel salón cada lunes o cada jueves, según el día que hubiéramos quedado, yo encendía el magnetofón, sacaba los cuadernos de notas y comenzábamos a hablar" (2013: 39). Las confesiones de Nevenka grabadas en el magnetofón presentan aquel material fijo característico de un informe periodístico, mientras que la forma en la que Millás manipula esa información, declarándose claramente de parte de la víctima, las cosas que decide contar y las que prefiere omitir, y las técnicas que utiliza, en cierta medida ficcionalizan, es decir, "novelizan" esas confesiones.

De la misma forma, Lozano hace claras alusiones a las conversaciones que obtuvo con la protagonista: "me comentó Zaida" (2015: 21). Aunque la autora no revela explícitamente cómo recolectó todo el material fijo para escribir la novela, sus fuentes se dejan deducir a lo largo de la obra. Así, las confesiones muy detalladas de Zaida encuentran su fundamento en un libro de notas, ya que "ha empezado a anotar todo lo que le ha ocurrido en el último año y medio, para que no se le olvide ni un solo detalle" (Lozano 2015: 91). Más adelante, Lozano deja constancia de que tuvo acceso a ese libro y otra documentación relevante al caso: "él nos ha dejado una carpeta con abundante documentación. Por cada hecho relatado hay un papel o grabación que lo atestigua" (2015: 220). 
Frente a la manipulación de los hechos y la versión oficial de la historia, Millás y Lozano deciden reordenar la información y reconstruir la realidad a través de la investigación, por lo que su discurso tiene una dimensión argumentativa. Así, los hechos, previamente bien conocidos a través la prensa, llegan al lector de otra forma -desde la perspectiva y la experiencia de la protagonista-, de manera que los autores se convierten en los intérpretes de aquellas historias. No mantienen la objetividad narrativa ni se distancian de los sucesos, no consideran distintas versiones de la historia ni disponen de la información obtenida por el agresor, más bien analizan con profundidad el personaje de Nevenka, o bien, Zaida, y la transformación que ha ocurrido en ellas, examinan el comportamiento de otros actores y critican, muchas veces explícitamente, a todos aquellos que de alguna u otra forma aportaron al acoso. Esto es, reconstruyen experiencias y hacen que el lector se ponga en el lugar de la víctima, de manera que provocan sentimientos como la solidaridad y la empatía. Esa identificación en la literatura viene determinada "tanto por la visión del mundo que el autor aporta al texto, por la actitud del narrador o por la actividad de los personajes como por la injerencia afectiva que se ejecuta en el proceso de interpretación" (Sánchez Zapatero 2011: 399).

En ese sentido, Lozano expresa su postura subjetiva desde los inicios de la novela: "La hoy comandante Cantera se ha decidido a relatar aquí su vivencia después de superar el miedo cerval que muchos militantes tienen a hablar" (2015: 13); "Se trata de nuestra versión: lo que ella me ha contado y lo que yo he comprobado, he visto y he vivido junto a ella" (2015: 14). Asimismo, se pone explícitamente de parte de la víctima e insiste en su inocencia: "Advierto de antemano a quienes lean estas páginas con lápiz rojo en la mano y alma de instructor de expedientes, que tendrán que encerrarme con ella ..." (2015: 14). En cierta medida, este enfoque justifica el carácter novelístico de la obra, ya que la historia presentada es el resultado de una selección intencional de datos y recursos hecha por la autora. De la misma forma, en una de las entrevistas que dio en El País comentando la obra, Millás afirma que escribió su novela contando únicamente con la perspectiva de Nevenka. No tenía intención de mostrar ambos puntos de vista ni de hacer comparaciones. Para explicar aquella decisión, Millás puso un ejemplo de la novela Relato de un náufrago de Gabriel García Márquez, donde el náufrago cuenta que cada día, a la misma hora, aparecían tiburones alrededor de su balsa. Era un hecho sobre el que nadie pidió la opinión de los tiburones. Siguiendo esa lógica, el autor afirmó: "Yo he recogido la experiencia de Nevenka; no me hizo falta preguntar a los tiburones" (S.f. 2004). Esa investigación parcial donde no se toman en consideración los testimonios de la otra parte se explica por el compromiso ético de ambos autores. Estos pretendían restaurar el equilibro entre la víctima y el acosador, ya que fueron los agresores los que recibieron un apoyo institucional y mediático desproporcionado.

Siendo Millás un hombre de letras que cultiva el periodismo literario, su experiencia y la fama de un escritor conocido a nivel internacional le han permitido inmortalizar la historia de Nevenka Fernández y convertirse en su protector. De hecho, en su entrevista en El País, se afirma que "siempre fantaseó con la 
idea de que un día alguien gritara buscando a un escritor en un lugar público, con el mismo énfasis con que se busca a los médicos" (S.f. 2004). Su necesidad de escribir esta historia incluso la refleja dentro del libro, donde el narrador homodiegético Juanjo -que lleva el mismo nombre que el autor- explica cómo fue desarrollándose su interés por el caso: "Por mi parte, recuerdo haber mantenido una atención irregular al suceso ..." (2013: 24); "La verdad es que mi interés por el 'caso Nevenka' tenía altibajos" (2013: 3). Relata, además, qué fue lo que finalmente le motivó a escribir la historia ("Fue la 'metamorfosis' que yo atribuía a Nevenka, y el silencio que se había establecido en torno a ella, lo que provocó mi interés" [2013: 27]) y qué pasos necesitaba tomar para recoger toda la información ("Tras escribir la columna y enviarla al periódico, me puse a hacer gestiones para localizar al abogado de Nevenka" [2013: 28]; "Necesitaba conocer a la joven y hablar con ella antes de tomar decisiones" [2013: 32]). Todas estas alusiones al proceso de creación de la obra aportan mutuamente a la objetividad -por su clara relación con la realidad-y a la subjetividad-por la identificación del autor como uno de los personajes que también comenta sus incertidumbres personales y mantiene conversaciones con otros personajes de la obra-. Por su parte, Irene Lozano, diputada nacional y portavoz de UPyD en comisiones de Defensa cuando se produjo el caso, se aprovecha de su posición para intentar ayudar a la víctima, tanto durante el juicio como a través de la escritura. La autora justifica de la siguiente manera su interés en publicar la historia de la militar acosada, basada en el abuso de poder y la corrupción en el Ejército español: "Desde el día en que conocí a Zaida, supe que había que contar su historia" (2015: 13); "Si hay una historia hoy en el Ejército que merece ser contada, es ésta" (2015: 14).

La presencia de los ecos autobiográficos en las dos obras pone de manera explícita un signo de igualdad entre la figura del narrador y del autor, de manera que el narrador se convierte en el portavoz del autor, hecho que fomenta la credibilidad y legitimidad de la narración. Así, los dos autores toman una posición narrativa donde se relacionan y se identifican con los elementos del relato. La implicación real de Lozano en el caso queda clara a lo largo de la obra, ya que la autora se introduce a sí misma como uno de los personajes del libro y se refiere a sí misma en primera persona, explicando cómo se realizó su primer contacto con el marido de Zaida: "Ha visto en redes sociales que una diputada de UPyD, Irene Lozano, ha defendido el caso de Zaida, y en las semanas previas al verano de 2013 se decide a escribirme un correo" (2015: 217). Con el fin de destacar esa involucración real, incluso revela el lugar o la fecha exactos de su primer encuentro con Zaida: "Nos encontramos un sábado por la mañana de junio de 2013 en una terraza de Madrid" (2015: 221). Además, con el mismo objetivo de dejar clara su presencia en el asunto, pero también con el fin de dirigir una crítica al organismo militar, la autora dedica todo un capítulo, titulado "El JEME y la diputada, frente a frente", a la reunión que sostuvo con el general Domínguez Buj. Cabe mencionar también el apartado de la "Introducción", firmado explícitamente por Irene Lozano, donde la autora insiste en la inocencia de su protagonista y se presenta como su defensora: "Advierto de antemano a quienes lean estas páginas con lápiz rojo en la mano y alma de instructor de expedientes, que tendrán 
que encerrarme con ella ..." (2015: 14). Explica, además, su necesidad de relatar la historia de Zaida, basada en el abuso de poder y la corrupción en el Ejército español: "Desde el día en que conocí a Zaida, supe que había que contar su historia" (2015: 13).

De igual forma, Millás hace sentir su presencia en la obra de manera constante, empatiza con la protagonista, toma partido y alude a las conversaciones que tuvo con los personajes-participantes del suceso: "Mira, Juanjo, creo que si alguien puede contar la historia de Nevenka, eres tú" (2013: 34); "Entonces me preguntó por qué quería contar su historia y me remití a los argumentos que ya había dado en la columna" (2013: 35).

Sin embargo, mientras en el principio de la obra, donde procuraba explicar su interés por el caso y su implicación real, Millás era el único narrador, posteriormente ese papel lo iba intercambiando con Nevenka, para que finalmente la experiencia en Inglaterra en su totalidad la contara ella misma en primera persona. Al informar brevemente al lector sobre los motivos del exilio de Nevenka y antes de citar literalmente su testimonio, el autor anunció de la siguiente manera tal narración de la protagonista: "Este es su relato" (2013: 183). De forma muy similar, Lozano introduce la historia de Zaida y se presenta como la narradora de los hechos, con breves, pero constantes intervenciones de la protagonista, para que el último capítulo del libro, titulado "Adiós a las armas" esté escrito y firmado explícitamente por Zaida, donde esta resume la experiencia vivida y agradece especialmente el apoyo de la autora de la novela.

Los dos autores establecen el contacto con los lectores, les hacen preguntas y los invitan a opinar sobre los sucesos. ${ }^{5}$ Esta técnica evoca el sentimiento de estar presente en los acontecimientos y formar parte de la historia. Expresando su opinión, Millás establece ese contacto con el fin de intensificar lo dicho y despertar empatía en el lector: "No había ninguna posibilidad, insisto, de que ese hombre no acabara con ella en la cama. Eso lo sé yo, lo sabe usted, lector, y lo sabe cualquiera con dos dedos de frente" (2013: 115). En el caso de la obra de Lozano, la autora, haciendo referencia a otras víctimas del teniente coronel Lezcano, le hace una serie de preguntas al lector, intentando involucrarlo en el relato y haciéndole pensar sobre la realidad de las mujeres acosadas en el ejército español:

\begin{abstract}
¿Por qué nunca denunciaron? ¿Sabían de antemano que en las Fuerzas Armadas tiene más posibilidad de arruinar su carrera la militar que denuncia que el mando denunciado? ¿No será que la mujer acosada sufre el doble castigo de verse menospreciada y vilipendiada por sus superiores? En suma, ¿no será esta una guerra invisible que está teniendo lugar dentro de las Fuerzas Armadas españolas sin que lo veamos, y cuyas víctimas no denuncian por miedo? ¿No será el clásico ambiente de impunidad en el que tiene más miedo a las consecuencias la víctima que el culpable? ¿No será un caso de doble victimización? (Lozano 2015: 128)
\end{abstract}

\footnotetext{
${ }^{5}$ Castany Prado (2007: 188) distingue dos tipos de lectores: el real y el implícito. El primero es el que realiza el acto de leer el libro y el segundo es la persona virtual a la que el autor tiene en mente cuando escribe su obra, intentando adaptar su escritura al gusto de ese lector potencial.
} 
Resumiendo el papel de los dos autores, se hace constar que "la intención de recordar y hacer presentes en el discurso sobre el pasado a aquellos cuya voz fue negada por su condición de víctimas o perdedores responde a un imperativo moral" (Sánchez Zapatero 2011: 395), esto es, que su obra cumple una función ética.

\section{LA ESTRUCTURA DE LAS NOVELAS TESTIMONIALES}

Las dos obras relatan historias reales e individuales, pero apelan a todo un colectivo de mujeres víctimas del acoso laboral o sexual.

En consecuencia, quien ha sido testigo -y víctima- de la barbarie, de la intolerancia, de la violencia o del horror y ha comprobado cómo su dolor ha sido ignorado al mismo tiempo que la intolerancia con la que se le trató ha sido legitimada hace de su testimonio -y del relato de la verdad de los hechos que incluye- un elemento a favor del conocimiento y de la ética. (Sánchez Zapatero 2011: 389)

El carácter extraoficial de No, mi general y Hay algo que no es como me dicen, esto es, el hecho de narrar la historia desde el punto de vista de la víctima crea la idea de un texto "sin ficción", pero con elementos de subjetividad y narración literaria.

Uno de los elementos literarios que se observa en este tipo de obras consiste en la falta de continuidad cronológica, ya que son característicos los saltos temporales o la inserción de episodios representativos, esto es, abunda la presencia de analepsis y prolepsis como recursos narrativos que consisten en trasladar una acción al pasado, o bien anticipar un evento determinado o hacer una pausa en la narración del presente para referirse a un suceso que tiene lugar en el futuro, respectivamente. Esa discontinuidad cronológica del texto responde al intento del autor de relacionar el suceso con sus consecuencias en la actualidad, o bien, con sus posibles causas que provienen del pasado, con la intención de referirse a los problemas similares de la sociedad o de mantener la intriga del lector. La obra de Millás, que comienza in media res, introduciendo al personaje de Nevenka en el pleno acto de su dimisión pública ante una rueda de prensa donde denunció por acoso sexual a su jefe, el alcalde Ismael Álvarez, tiene una interpretación doble. Por una parte, el autor parece estar de acuerdo con la norma periodística que requiere la prioridad de los hechos fundamentales, y por otra, evita la estructura lineal, siguiendo las pautas de la ficcionalidad. Ese rasgo ficcional lo explica el propio autor, señalando que "la personalidad de Nevenka estaba llena de datos novelescos" (2013: 37).

Así, Millás parte de ese evento central y durante unos capítulos sigue narrando la historia en orden cronológico (presenta su interés en el caso y su primer encuentro con Nevenka), para luego dar un giro hacia el pasado, contando el período de la vida de Nevenka poco antes de iniciar su baja por depresión. A partir de ahí, vuelve a seguir el orden cronológico explicando su estado psicofísi- 
co, su primera cita al psiquiatra, la falta de comprensión por parte de sus padres, su mudanza a Madrid a casa de los padres de su novio Lucas, el encuentro con Charo Velasco, del PSOE, la decisión de interponer una denuncia contra su jefe y el acuerdo con su abogado Adolfo Barreda. En ese momento el lector todavía desconoce la propia situación de acoso, aunque el autor le permite descubrir algunos detalles que le precedieron, como el hecho de que durante unos meses Nevenka había tenido una relación consentida con el alcalde. Al haber presentado el marco de la historia que abarca el período desde la baja hasta la denuncia, Millás abandona nuevamente ese orden cronológico y recurre a la retrospección motivada por la intención de descubrir los antecedentes en la vida de Nevenka que pudieron haber provocado el acoso, haciéndose a sí mismo la pregunta: "¿Pero cuándo había empezado realmente ese proceso de extrañamiento 6 respecto de su propio mundo?" (2013: 109). Esta pregunta arranca una serie de sucesos previos al acoso, que el autor analiza con la intención de explicar el comportamiento de Nevenka (descubre las marcas que esta lleva desde su nacimiento -su origen y el origen de su nombre- y hace referencia a su educación y su personalidad). Analizando esos factores y sucesos del pasado de la protagonista, Millás procura profundizar en el propio tema del acoso ejercido y justificar el comportamiento de Nevenka, de manera que su postura a lo largo de toda la novela nunca es neutral. Posteriormente, vuelve a trasladar la narración a los momentos previos a la denuncia, explicando el cambio en la personalidad de Nevenka, la búsqueda y preparación de las pruebas con ayuda de su psiquiatra de Madrid. Millás necesitaba presentar todos estos antecedentes y crear un fondo de la historia antes de explicar los inicios de Nevenka en el Ayuntamiento, los acercamientos sutiles y las manipulaciones del alcalde, así como su corto noviazgo. Contando con esa información, el lector puede finalmente conocer las situaciones concretas del acoso, tanto laboral como sexual, que sufrió Nevenka. Creando esta estructura del relato, el autor en cierta manera defiende a la protagonista, impidiendo al lector juzgarla sin tener en cuenta todos los factores previos al acoso.

El ejemplo más claro de dicha discontinuidad en la obra de Millás queda reflejado en un episodio presentado por el capítulo "La reaparición de Lucas", que relata el comienzo del noviazgo de Nevenka y Lucas. Este capítulo aparece interrumpiendo la historia sobre las habitaciones comunicadas -situación del acoso sexual más grave ejercido sobre Nevenka-, y como tal, tiene doble función. Por una parte, sirve para contradecir con el optimismo de iniciar una relación amorosa a la incapacidad total de defenderse ante una relación forzosa, y por otra, señala la importancia del papel de Lucas en la superación del acoso.

Millás cierra el círculo de múltiples viajes temporales, volviendo a los momentos posteriores a la denuncia, que fue justamente como empezó la novela, -in media res-. Finalmente, relata el exilio de Nevenka a Inglaterra y muy breve-

\footnotetext{
6 Fauquet (2011: 262) interpreta ese "extrañamiento" como condición de acceso a la autonomía, ya que la protagonista tenía que ver sus ilusiones sobre el mundo en el que vivía derrumbadas a causa del acoso, para empezar a cuestionar la realidad en la que se educó y desarrollar paulatinamente su autenticidad.
} 
mente el juicio. Así, bajo el nombre "Los restos de Nevenka", el primer capítulo presenta un verdadero contraste al último titulado "Nace la otra Nevenka". Este esquema con dos puntos extremos sugiere que "el camino recorrido por $\mathrm{Ne}$ venka es un proceso vital inverso, de la muerte al renacimiento" (Fauquet 2011: 264), pero también señala el triunfo matizado de Nevenka, ya que la historia termina "con la víctima feliz, pero exiliada, y el agresor protegido por la solidaridad y el cariño de los suyos" (Millás 2013: 202).

En cuanto a la obra de Lozano, la autora ya en la parte introductoria revela el final de la historia de Zaida, por lo que la novela empieza in extrema res: "Como única vía de escape para acabar con esta sinrazón, Zaida ha solicitado la salida del Ejército" (2015: 12). Hablando de la preparación de la portada del libro, incluso señala que en el momento de su publicación Zaida había abandonado definitivamente el Ejército: "Pensé con tristeza que una mujer valiente y recia como ella nunca imaginó que vestiría su uniforme por última vez en un estudio fotográfico" (2015: 15). Más adelante, al introducir el motivo por el que escribe la obra, la autora empieza a relatar la historia de Zaida partiendo de su vuelta de una misión internacional en el Líbano y situándola en su casa familiar en Valencia. Hace un breve recorrido al pasado, con el fin de explicar en qué consistía aquella misión y el trabajo de Zaida en general, empezando así a construir su personaje.

Así, anunciando la vuelta de Zaida a la base, después de haber estado en el Líbano, la autora se apoya en la prolepsis, adelantando los acontecimientos y haciendo alusión al acoso que se ejercerá: "En ese momento no imagina que es la última vez, no sabe que estos han sido sus últimos días de tranquilidad y que en España, en unas pocas semanas, conocerá el infierno" (2015: 26).

La narración sobre la reincorporación a la base, donde empezaron las situaciones del acoso, primero sexual y posteriormente laboral, sigue una estructura lineal hasta el momento cuando Zaida se da cuenta de que sus otros superiores ignoran el asunto y no pretenden sancionar a su acosador. En ese momento, la autora rompe con esa cronología lineal, introduciendo dos capítulos independientes, pero relacionados entre ellos, sobre la formación de Zaida y sus inicios en la Academia Militar. Al igual que Millás, Lozano lo hace para profundizar en la personalidad de su protagonista y enfatizar su desventaja por su simple condición de mujer, ya que no resulta suficiente con que el lector conozca solamente el caso concreto del acoso para empatizar o identificarse con la víctima.

Así, en el capítulo "La nadadora que quiso ser militar", se presenta la situación familiar de Zaida, su educación y la decisión de hacerse militar. Lozano interrumpe muy brevemente esa narración contrastando el entusiasmo que caracterizaba a la protagonista en esos momentos con su estado actual:

Ahora, en medio del tormento en que han convertido su vida, le parece increíble la ilusión con la que aquella adolescente decidió ingresar en el Ejército. Al recordar a aquella chiquilla inquieta y sacrificada, dispuesta a comerse el mundo, le parece que se trata de otra persona casi podría decirse que lo era. (Lozano 2015: 59) 
Más adelante, relatando las dudas que Zaida tenía durante las pruebas de la Academia Militar, la autora hace un breve salto al presente: "Y es curioso, pero no volvió a preguntarse qué hacía allí hasta que fue víctima del acoso sexual y laboral del teniente coronel Lezcano" (2015: 63).

Lozano alterna estas dos retrospecciones con el relato principal, insistiendo en los detalles de las situaciones de hostigamiento, la agresión física, la denuncia, y, como consecuencia de ello, el traslado forzoso de Zaida a Sevilla. Posteriormente, sigue con una estructura lineal, centrando la narración en los testimonios en el juicio, la sentencia producida y las consecuencias que esta ha provocado en el futuro profesional de Zaida, creando nuevas intolerancias hacia ella y nuevas manifestaciones de acoso. Estas implican situaciones de persecución, la involucración directa de la autora en el asunto, así como la denuncia por supuesta falsificación contra Zaida. La novela acaba dejando claro por qué Zaida ya no viste el uniforme militar, dato que el lector conoce desde el principio de la obra, de manera que la autora crea una narración circular.

En uno de los episodios que intercala en la narración central, Millás se dedica a analizar los aspectos principales del libro El acoso moral de Marie-France Hirigoyen, regalo del abogado Adolfo Barreda para Nevenka, con el fin de aumentar la objetividad, presentar el fenómeno de acoso desde una perspectiva científica y justificar así el estado de su protagonista. Esa objetividad se refleja en su totalidad en el momento cuando el autor cita un fragmento de dicho libro, incluyendo incluso la página en la que este figura:

No solo describía su situación, sino que a veces parecía leerle el pensamiento, como cuando en la página 68 de la edición española dice: "Presentar una denuncia es la única manera de terminar con el psicoterror. Pero hay que tener mucho valor o haber llegado verdaderamente al límite, pues implica una ruptura definitiva con la empresa. Por otra parte, no hay ninguna garantía de que la denuncia prospere, ni de que desemboque en un resultado positivo". (Millás 2013: 106)

Así, mediante distintas fuentes extratextuales, entre ellas datos estadísticos, fragmentos de la sentencia e informes de psicólogos y psiquiatras a los que acudió su protagonista, Millás ofrece datos verificables, afirmando así la naturaleza documental de su obra.

Con el mismo fin de respaldar la objetividad de su narración, Lozano cita un párrafo de las Reales Ordenanzas, hace referencia a una entrevista a la ministra de Defensa en la revista Mujer Hoy o expone los datos estadísticos sobre la presencia real de la mujer en el Ejército español: "En el caso del Ejército de Tierra, de sus 25.017 cuadros de mando 'combatientes' (oficiales y suboficiales de carrera) solo 663 son mujeres; de estas, solo 90 son oficiales, es decir, representan 1,1 por ciento según datos oficiales de las propia Fuerzas Armadas en 2014" (2015: 84). De igual manera, pone en evidencia el contenido entero de la carta que Zaida mandó al Observatorio de la Mujer de las FAS, hace referencia a algunas partes del informe del psicólogo (lo mismo hace Millás con los informes de psiquiatras de Nevenka) o de la carta que Zaida dirigió al ministro de Defensa, 
Pedro Morenés, o bien, deja constancia de un artículo en El Mundo publicado sobre el caso de Zaida y la sentencia del Lezcano, citando su título, el nombre de los autores y una parte del texto. Aparte de dichos ejemplos, la autora consigue la máxima objetividad probablemente dejando en evidencia, como prueba documental del acoso ejercido, una copia escaneada de la solicitud de permiso que Zaida rellenó para ausentarse unos días de un curso que estaba realizando, misma por la que posteriormente se le acusaría por un delito de falsificación y deslealtad. La autora explica detalladamente la naturaleza de tal documento y su carácter informal, con la intención de respaldar a la víctima y explicarle al lector que tal situación en realidad ha servido de mera excusa para seguir con la persecución.

Lo que también aporta a la objetividad del relato es el lenguaje directo, claro, en muchas ocasiones coloquial, pero también analítico y puntualizador. Millás se apoya constantemente en ese aspecto analítico del lenguaje, mostrando su opinión y estudiando los elementos que pudieron haber provocado el acoso ("siempre en mi opinión", "tengo para mí", "personalmente, creo que ..."). Asimismo, utiliza el lenguaje simple, coloquial y cercano al lector, por una parte, y el vulgar para intensificar la personalidad del acosador, por otra: "Nevenka era una 'niña bien' de Ponferrada, una 'pija' por decirlo rápido" (2013: 90); "Eres una hija de puta y yo voy a ser más hijo de puta contigo" (2013: 154).

Lozano también utiliza el lenguaje vulgar para, a través del monólogo interior y reflexiones de Zaida, intensificar el estado de rabia en el que se encuentra la protagonista: "¡Este baboso hijo de puta acaba de proponerme una transacción sexual!" (2015: 38); "Todo el mundo sufre los atropellos del hijo de puta..." (2015: 68); "Ese hijo de la gran puta es capaz de sacar la pistola y meterme un tiro" (2015: 95). Otro de los recursos del lenguaje que utiliza esta autora es la ironía de disimulo, esto es, la ironía que consiste en "evitar toda afirmación propia y en poner preguntas aparentemente inocentes, pero capciosas para el interlocutor" (Lausberg 1967: 290). Así, la narradora-personaje, Irene Lozano, cita a sí misma en una intervención dirigida al ministro de Defensa, donde intenta criticar públicamente su falta de interés en el caso de Zaida:

El día del debate en el Pleno, comienzo mi intervención avergonzando al ministro Morenés con una ironía: "Señor ministro, en primer lugar, me alegro de verle. Le he llamado por teléfono cuatro o cinco veces en las últimas dos semanas y, al no devolver la llamada, estaba preocupada por su salud. Me alegro de que esté bien". (Lozano 2015: 222-223)

Los prólogos y epílogos con los que cuentan estas novelas testimoniales son otros de los elementos que tienen el objetivo de convencer de la veracidad de lo ocurrido. En el epílogo de su obra, Millás medita sobre la confirmación de la sentencia y la falta de reacción de los periódicos y los políticos. Además, el autor permite conocer la época en la que escribió el epílogo, usando la fecha exacta como un tipo de expresión máxima de objetividad: "Pasados unos días desde la confirmación de la sentencia y con el libro terminado, decidí viajar a la ciudad 
del norte de Europa donde Nevenka y Lucas vivían desde el mes de agosto de 2003" (2013: 200).

En No, mi general el prólogo viene sustituido por la "Introducción" escrita y firmada explícitamente por Irene Lozano, mientras que el epílogo es un tanto particular, ya que enumera los nombres y apellidos de los cargos militares que directa o indirectamente ejercieron el acoso sobre Zaida, hace referencia a su implicación en el caso y presenta su situación actual. Dejando a Zaida al final de esa lista, la autora procura mostrar que, a pesar de dos juicios realizados a favor de ella, la más perjudicada es precisamente la víctima, ya que el resto de los nombrados que aparecen en la lista ejercen sus funciones sin mayores impedimentos.

En cuanto a la subjetivización del relato, aparte de los elementos ya mencionados, estas novelas aumentan su grado de ficcionalidad utilizando la inserción de diálogos o el monólogo interior. Con el primero se consigue la fluidez de la narración, mientras que el segundo permite exteriorizar los pensamientos de los personajes, profundizar en su carácter y establecer una relación más cercana con el lector. Puesto que los hechos se comunican siempre desde una sola perspectiva, es decir, que el autor no es omnipresente, la experiencia de la protagonista sirve de fuente informativa principal, tanto para explicar los hechos ocurridos, como para transmitir sentimientos y pensamientos íntimos. Así, el hecho de que la autora de No, mi general utiliza de manera abundante la técnica del monólogo interior para expresar los pensamientos de Zaida respalda la teoría de la subjetivización de la novela testimonial, ya que, en caso contrario, no podría conocer sus pensamientos internos ni citarlos literalmente: "Los pensamientos empiezan a sucederse en su cabeza a borbotones: 'Vaya, parece que los peores rumores sobre este tipo se confirman ..." (2015: 29); "Eso mismo piensa Zaida: 'Llevo diez años en el Ejército y nunca he vivido nada parecido. Esto no es normal ..." (2015: 34); "Ella piensa: 'No se trata de que vaya con cuidado, sino de que alguien haga algo'" (2015: 36); "'He debido de ser muy trasto para que mi padre no se acuerde de mí', pensó" (2015: 60); "En ese momento, piensa: 'Se acabó; conmigo vale, pero con los míos, no'" (2015: 90).

Los diálogos, por su parte, caracterizan toda su obra, teniendo una presencia dominante en los testimonios del juicio, lo que permite que el lector visualice la situación y la viva desde cerca. La autora reconstruye esos diálogos a través de las conversaciones que Zaida mantuvo con otros interlocutores. Además, en una ocasión, Lozano incluso cita un dialogo entre el teniente coronel Andrade y un oficial, en el que ni siquiera Zaida participó: "Está obsesionado con ella, mi teniente coronel. Solo preguntaba por ella. Decía que quería cogerla y que la estaba esperando" (2015: 52). Nuevamente, esto demuestra los rasgos ficticios de la obra, ya que, sin ni siquiera contar con una fuente de información fiable, era imposible que la autora conociera con certeza el desarrollo de esa conversación.

Millás, por su parte, recurre mucho a los diálogos que Nevenka establece con algún personaje (sus padres, Lucas, Ismael, psiquiatras), o bien, lo hace él mismo (con Nevenka, Señor Invisible, Lucas). De esta forma, hace saber que una 
parte del material para escribir la novela la consiguió a través de conversaciones que mantuvo con otros testigos, entre ellos el novio de la protagonista: "Lucas [...] me diría que se sentía como un espía paseando al perro mientras la concejal del PP y la portavoz del PSOE hablaban" (2013: 86)". Estos testigos siempre se definen por ser aliados de Nevenka, ya que a Millás le interesa únicamente la versión de la víctima.

Así, recurriendo constantemente a diálogos y monólogos, los dos autores consiguen convertir al lector en partícipe activo de la historia y provocar en él una fuerte sensación de formar parte de ella.

\section{CONCLUSIÓN}

Resumiendo el análisis presentado y partiendo de una postura más global, se concluye que lo que define a la narrativa española actual es la "búsqueda incesante de nuevos caminos, de nuevos procedimientos para mostrar nueva realidad, la del momento, cada vez más compleja y fluctuante" (Valls Guzmán 2003: 36). Esta nueva realidad creada en las dos novelas analizadas se caracteriza por su carácter tanto documental como narrativo. Por una parte, se distingue una serie de técnicas que objetivizan los hechos (la implicación real del autor, el material fijo, datos estadísticos y verificables en el mundo real, fechas y lugares exactos, prólogo y epílogo, el lenguaje) y, por otra, se detectan unos mecanismos que aportan a la subjetivización del relato (el autor como personaje del libro, la narración desde la perspectiva de la víctima, la discontinuidad cronológica, el contacto con el lector, diálogos y monólogo interior, el presente narrativo). La naturaleza testimonial de las dos novelas queda reflejada también en dos niveles diegéticos del relato que se superponen constantemente: la historia del narrador (Millás o Lozano que investigan e informan sobre los sucesos) y la de la protagonista (Nevenka o Zaida que se interpretan como objeto de esa investigación).

Estudiar estos elementos ha permitido confirmar el carácter colectivo y denunciatorio de las dos novelas, acercando la narrativa actual a los problemas emergentes de la sociedad. En términos más generales, esto quiere decir que, en palabras de Navajas Navarro, "la ficción española narra desde hechos y perspectivas singulares pero en íntima conexión con orientaciones generales" (2002: 80). De ahí la especial importancia de No, mi general y Hay algo que no es como me dicen, que hablan en nombre propio, pero adquieren una dimensión modélica y apelan a todo un colectivo de mujeres víctimas del acoso sexual, fenómeno cuya problemática se relaciona principalmente con un contexto social en el que las mujeres son valoradas por su papel sexual antes que por el profesional. De esta forma, las dos novelas permiten establecer un vaivén constante entre un caso real concreto, por una parte, y los mecanismos y las manifestaciones del acoso en el lugar de trabajo, por otra.

OBRAS CITADAS

Amar Sánchez, Ana María (1990). "La ficción del testimonio", Revista Iberoamericana, 151: 
447-461.

Amar Sánchez, Ana María (1992). El relato de los hechos. Rodolfo Walsh: testimonio y escritura. Rosario: Beatriz Viterbo Editora.

Augusto Ayuso, C. (2001). "Para un acercamiento a la narrativa de Juan José Millás", Castilla: Estudios de literatura, 26: 19-34.

Beverley, John (1987). "Anatomía del testimonio", Revista de Crítica Literaria Latinoamericana, 13.25: 7-16.

Castany Prado, Bernat (2007). Literatura posnacional. Murcia: Universidad de Murcia, Servicio de Publicaciones.

Chillón, Albert (1999). Literatura y periodismo. Una tradición de relaciones promiscuas. Barcelona: Universidad Autónoma de Barcelona.

Duplaá, Christina (1996). La voz testimonial de Montserrat Roig: estudio cultural de los textos. Barcelona: Icaria.

Fauquet, Isabelle (2011). "Trayectorias ejemplares en Hay algo que no es como me dicen. Caso de Nevenka Fernández contra la realidad, de Juan José Millás", in La ejemplaridad en la narrativa española contemporánea (1950-2010), ed. Amélie Florenchie e Isabelle Touton. Madrid/Frankfurt: Iberoamericana/Vervuert, 259-277.

González Harbour, Berna (2014). "La realidad asalta la ficción", El País. <http://cultura.elpais.com/cultura/2014/12/03/babelia/1417632850_236816.html> (12 de marzo de 2020).

Gugelberger, Georg, y Michael Kearney (1991). "Voices of the Voiceless: Testimonial Literature in Latin America", Latin American Perspectives, 18.3 (parte I): 3-14.

Huertas Uhagón, Begoña (1994). "El postboom y el género testimonio. Miguel Barnet". Cauce: Revista de filología y su didáctica, 17: 165-176.

Lausberg, Heinrich (1967). Manual de Retórica Literaria. Fundamentos de una ciencia de la literatura, tomo II. Madrid: Gredos.

Lejeune, Philippe (1994). "El pacto autobiográfico (1973)", in El pacto autobiografico y otros estudios, dir. Francisco Jurdao Arrones, trad. Ana Torrent. Madrid: Megazul-Endymion, 49-88.

Lozano, Irene (2015). No, mi general. Barcelona: Penguin Random House.

Millás, Juan José (2013). Hay algo que no es como me dicen. El caso de Nevenka Fernández contra la realidad [2004]. Barcelona: Seix Barral.

Navajas Navarro, Gonzalo (2002). La narrativa española en la era global. Imagen. Comunicación. Ficción. Barcelona: EUB.

Sánchez Zapatero, Javier (2011). "Escritura autobiográfica y traumas colectivos: de la experiencia personal al compromiso universal", Revista de Literatura, 73.146: 379-406.

S.f. (2004). "Juan José Millás cree que Nevenka le honró al confiar en él", El País. <http:// elpais.com/diario/2004/03/02/madrid/1078230279_850215.html> (25 de marzo de 2020).

Sobejano, Gonzalo (1986). "Testimonio y poema en la novela española contemporánea", in Actas del VIII Congreso de la Asociación Internacional de Hispanistas, ed. A. David Kossoff et al. Madrid: Istmo, 89-115.

Sobejano, Gonzalo (2007). Lección de novela (España entre 1940 y ayer). Madrid: Mare Nostrum.

Torregrosa Carmona, Juan Francisco, y Carmen Gaona Pisonero (2013). "Antecedentes y 
perspectivas sobre periodismo literario español durante el siglo xx", Historia y Comunicación Social, 18 (núm. Especial Octubre): 789-798.

Valls Guzmán, Fernando (2003). La realidad inventada. Análisis crítico de la novela española actual. Barcelona: Crítica. 